\title{
SISTEM TRANSMISI DATA ELEKTROMAGNETIK DENGAN MODUL RF XBEE UNTUK MENGETAHUI PENGARUH FUNGSI SPASIAL DAN FUNGSI TEMPORAL TERHADAP PROSES TRANSMISI GELOMBANG ELEKTROMAGNETIK
}

\author{
Aprilian Eka $S^{1}$, Yayan Prima $\mathbf{N}^{1}$, Hanif $\mathbf{B}^{1}$, Mashudi ${ }^{1}$, Adiyatno $\mathbf{M}^{1}$ \\ ${ }^{1)}$ Program Studi Fisika, FMIPA, Universitas Negeri Surabaya \\ Email : yans.okx@gmail.com
}

\begin{abstract}
Computational Laboratory work based research and development is an implementation of the study of physics topics of Electromagnetic Waves. In this physical event it will be studied in the treatment of Electromagnetic Waves transmit information. Delivery Information in this study using the XBee modules as media delivery and acceptance of this research will be tested how the XBee modules were subjected to the measurement of the spatial variation influences the efficiency of data transmission. Change the time variation performed three times for each variation of the distance change measurements. The third shows the time variation of the same relative results are collecting data at 5:00 to 7:00 showed the best distance is obtained at a distance of $\leq 75 \mathrm{~m}$, while for a distance of $80 \mathrm{~m}$ to $85 \mathrm{~m}$ of data at the receiver experiencing annihilation one character at a distance of $90 \mathrm{~m}$ and the data can not be accepted at all by the recipient. The data at 14:00 to 16:00 showed similar results also with the data obtained in the 20:00 to 22:00, that all significant data with the data of data at 5:00 to 7:00. The conclusion that can be drawn is that there is no significant effect of changes in -time delivery of data.
\end{abstract}

Keywords: Xbee, Electromagnetic Waves

\begin{abstract}
Abstrak
Penelitian berbasis Laboratorium dan Komputasional ini merupakan implementasi dari pengembangan topik kajian fisika tentang Gelombang Elektromagnetik. Pada peristiwa fisis ini akan diteliti tentang perlakuan Gelombang Elektromagnetik dalam mengirimkan informasi. Pengiriman Informasi dalam penelitian ini menggunakan modul Xbee sebagai media pengiriman dan penerimaan. Dalam penelitian ini akan diuji bagaimana modul Xbee diberi perlakuan variasi spasial pengukuran terhadap pengaruh efisiensi pengiriman data. Perubahan variasi waktu dilakukan tiga kali untuk setiap variasi pengukuran perubahan jarak. Dari ketiga variasi waktu menunjukkan hasil yang relatif sama yaitu pengambilan data pada pukul 5.00-7.00 menunjukkan jarak terbaik diperoleh pada jarak $\leq 75 \mathrm{~m}$, sedangkan untuk jarak $80 \mathrm{~m}$ hingga $85 \mathrm{~m}$ data pada penerima mengalami pelenyapan satu karakter dan pada jarak $90 \mathrm{~m}$ data tidak dapat diterima sama sekali oleh penerima. Data pada pukul 14.00-16.00 menunjukkan hasil yang sama pula dengan data yang diperoleh pada 20.00-22.00, yaitu semua data signifikan dengan data data pada pukul 5.00-7.00. Kesimpulan yang dapat diambil adalah tidak terdapat pengaruh yang cukup signifikan perubahan waktu pengiriman data.
\end{abstract}

Kata Kunci: Xbee, Gelombang Elektromagnetik 


\section{PENDAHULUAN}

Pesatnya perkembangan ilmu pengetahuan dan teknologi ditandai dengan banyaknya penelitian dalam bidang telekomunikasi yang semakin kompleks (Rao, 2005: 6). Pengaruh bidang komunikasi yang menyertakan berbagai komunitas turut menyumbangkan kemajuan telekomunikasi digital (Nugraha, 2013: 1). Kelahiran sistem telekomunikasi digital dengan berbagai varian divais telekomunikasi baru yang lebih canggih dan fleksibel adalah hal yang tidak bisa dipungkiri (Ergen, 2005: 1). Dalam sebuah sistem telekomunikasi dan sistem informasi digital saat ini banyak yang menerapkan sistem aplikasi nirkabel sebagai media transfer informasi dari satu instrumen komunikasi ke instrumen komunikasi lain (Nugraha, 2013: 1). Fenomena fisis yang dapat dimanfaatkan sebagai media transfer informasi nirkabel merupakan perpaduan komposisi sempurna dari fluktuasi medan listrik dan medan magnet yang menjalar saling tegak lurus terhadap arah rambat gelombang.

Dalam sebuah Literatur fisika (Griffiths, 1999: 381) disebutkan bahwa besaran yang digunakan untuk mendeskripsikan kerapatan energi elektromagnetik dikenal sebagai vektor Poynting. Besaran fisis ini didefinisikan sebagai perambatan energi elektromagnetik dalam arah normal terhadap arah medan listrik dan medan magnet. Secara matematis, vektor Poynting dituliskan sebagai

$$
\vec{S}=\frac{1}{\mu_{0}} \overrightarrow{E_{0}} \times \overrightarrow{B_{0}}
$$

dengan $\vec{S}$ adalah vektor Poynting yang menyatakan besaran fisis terukur intensitas medan elektromagnetik. Persamaan (1) tersebut di atas menceritakan bahwa kerapatan energi elektromagnetik sebanding dengan kuadrat amplitudo dan berpindah dalam ruang waktu dengan arah sesuai dengan arah perambatan gelombang.

Berbeda dengan kasus perambatan dalam vakum atau di udara, maka perambatan gelombang elektromagnetik dalam bahan konduktor mengalami atenuasi dalam bentuk pelemahan amplitudo sebagai fungsi jarak tembus terhadap bahan. Secara matematis, hal ini dituliskan sebagai Persaman (2) dan Persamaan (3) berikut:

$$
\begin{aligned}
& \vec{E}=\overrightarrow{E_{0}} e^{-K z} \sin (k z \pm \omega t) \\
& \vec{B}=\overrightarrow{B_{0}} e^{-K z} \sin (k z \pm \omega t)
\end{aligned}
$$

dimana $\overrightarrow{E_{0}}$ dan $\overrightarrow{B_{0}}$ adalah amplitudo medan listrik dan medan magnet, sedangkan $k=\frac{2 \pi}{\lambda}$

dengan $\lambda$ adalah panjang gelombang dan $\omega=2 \pi v$ adalah kecepatan osilasi gelombang dengan $v$ adalah frekuensi gelombang. Hubungan antara panjang gelombang $\lambda$ dan frekuensi gelombang $v$ adalah $c=v \lambda$, yang jelas menunjukkan penurunan amplitudo secara eksponensial dalam arah perambatan gelombang.

Untuk kasus perambatan gelombang elektomagnetik dalam bahan konduktor, Griffiths (1999: 394) menuliskan bahwa laju penurunan energi elektromagnetik diukur dengan besaran skin depth yang didefinisikan sebagai jarak terukur dalam bahan dimana energi elektromagnetik berkurang menjadi 1/e.

Modul RF yang digunakan dalam proses penelitian ini adalah Xbee, yang mana modul ini bekerja pada range tegangan antara (2.4 - 3.4) volt. Implementasi dari modul RF Xbee tersebut dapat dimanfaatkan untuk keperluan komunikasi data perumahan, hotel maupun dalam bentuk bangunan (Rao, 2005: 6). Modul ini dapat dimanfaatkan seperti jaringan komputer lain secara Ad-Hoc (Jamil, 2008). Penelitian sistem propagasi dalam (Nugraha, 2013: 3) Xbee Seri 1 ini bekerja dalam dua fungsi yang berbeda, yaitu fungsi individu yang artinya modul ini sudah dapat dimanfaatkan sebagai media telemetri untuk menyampaikan informasi baik analog maupun digital I/O. 
ISSN: 2087-9946

\section{METODE PENELITIAN}

Sistem pengiriman modul Xbee dengan manipulasi jarak antar transmiter dengan receiver, menunjukan pengaruh jarak yang berperan besar dalam pengiriman data, pada umumnya perangkat elektronik yang berbasis sistem transmisi nirkabel mempunyai batasbatas jarak yang telah ditentukan. Untuk sistem yang digunakan dalam penelitian ini yaitu modul Xbee yang memiliki jarak jangkau berkisar $90 \mathrm{~m}$ untuk lapangan terbuka dan berkisar 30 meter untuk ruangan tertutup. Modul yang digunakan diintegrasikan melalui sebuah sistem mikrokontroler dengan memanfaatkan Atmega 8 sebagai prosesornya. Sistem clock yang digunakan juga menggunakan internal sebesar $1 \mathrm{MHz}$. pengiriman data dilakukan dengan memanipulasi jarak yaitu dimulai dari jarak $1 \mathrm{~m}, 5 \mathrm{~m}$, dan kelipatan $5 \mathrm{~m}$ hingga jarak optimum $90 \mathrm{~m}$ sesuai datasheet. Data yang dikirimkan berupa karakter ASCII yaitu huruf ' $x$ ', ' $y$ ', ' $z$ '. Data dikirimkan dengan delay waktu satu detik. Waktu tunda ini diharapkan mampu memberikan jeda penglihatan kepada pengamat agar mudah dalam mencatat data yang masuk. Selain hal tersebut, maka data yang dikirimkan ini merupakan data yang sequensial, artinya data yang dikirim merupakan data yang berkelanjutan setiap satu looping squensial mode.

Pengiriman data dilaksanakan dalam tiga kali waktu pengambilan data yang dapat ditentukan antara pukul 05.00-07.00, pukul 14.00-16.00, dan pukul 20.00-22.00. Perbedaan waktu pengukuran ini didasarkan atas pengujian pengaruh cuaca dengan lebih tepatnya temperatur mempengaruhi proses pengiriman data. Pengujian dilakukan di lapangan yang terbuka dan tidak ada penghalang sama sekali. Pengujian ini dimaksudkan untuk mengetahui efektivitas pengiriman data pada semua temperatur. Untuk teknik pengambilan data dengan variasi perubahan jarak dan perbedaan waktu pengambilan dapat dilihat pada gambar 1 .

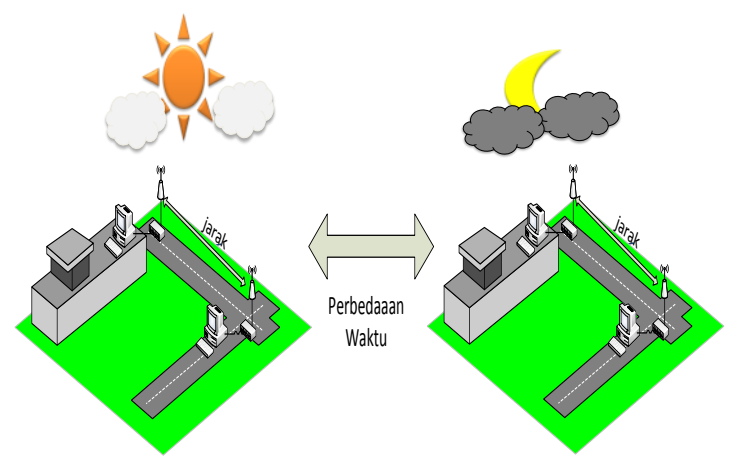

Gambar 1. Pengambilan data dengan manipulasi perbedaan waktu

\section{HASIL DAN PEMBAHASAN}

Penelitian laboratorium dan lapangan yang talah peneliti lakukan berbasis pemanfaatan gelombang elektromagnetik untuk memindahkan informasi dari suatu tempat menuju tempat lain. Pada penelitian ini dilakukan beberapa variasi perubahan faktor spasial untuk mengetahui perubahanperubahan informasi yang telah ditransmisikan. Perubahan informasi yang telah dikirimkan tentunya erat kaitanya dipengaruhi oleh beberapa faktor fisis yang mungkin dapat mengganggu proses trasnmisi data. Selain itu jangkauan data yang telah dipancarkan dipengaruhi juga oleh besarnya energi pancar yang telah ada pada pemancar tersebut. Hal lain yang mempengaruhi adalah waktu pengambilan data yang dipengaruhi secara langsung oleh perubahan kondisi cuaca baik berupa data kelembapan maupun pengaruh suhu dan beberapa gangguan lain yang dapan memberikan noise pada pengiriman data tersebut. Berikut adalah data yang dapat terkirim dengan pengaruh perubahan faktor spasial. Data awal yang diperoleh merupakan data yang diperoleh pada saat kondisi pagi hari dengan kondisi cuaca cerah.

Tabel 1. Hasil pengambilan data pukul $5.00-7.00$

\begin{tabular}{|c|c|c|}
\hline No & Jarak (m) & Data $S$ dan $R$ \\
\hline 1 & 1 & 'x';'y';'z' \\
2 & 5 & 'x';'y';'z' \\
3 & 10 & 'x';'y';'z' \\
4 & 15 & 'x';'y';'z' \\
5 & 20 & 'x';'y';'z' \\
\hline
\end{tabular}




\begin{tabular}{|c|c|c|}
\hline No & Jarak (m) & Data $S$ dan $R$ \\
\hline 6 & 25 & 'x';'y';'z' \\
7 & 30 & 'x';'y';'z' \\
8 & 35 & 'x';'y';'z' \\
9 & 40 & 'x';'y';'z' \\
10 & 45 & 'x';'y';'z' \\
11 & 50 & 'x';'y';'z' \\
12 & 55 & 'x';'y';'z' \\
13 & 60 & 'x';'y';'z' \\
14 & 65 & 'x';'y';'z' \\
15 & 70 & 'x';'y';'z' \\
16 & 75 & 'x';'y';'z' \\
17 & 80 & 'x';'z' \\
18 & 85 & 'x';'z' \\
19 & 90 & lenyap \\
\hline
\end{tabular}

$\mathrm{R}$ : receiver $; \mathrm{S}=$ source ;

Data diambil pukul 5.00-7.00

Tabel 1 di atas menunjukkan hasil-hasil pengambilan data yang dilakukan pada waktu pagi hari dan cuaca cerah. Kategori cuaca dalam keadaan cerah adalah di mana tidak terjadi hujan maupun cuaca berawan. Keadaan ini kuga ditandai dengan kondisi tidak adanya angin di sekitar lokasi pengambilan data. Data-data yang diperoleh dari jarak pengukuran $1 \mathrm{~m}$ hingga jarak pengukuran $75 \mathrm{~m}$ mengalami kondisi yang baik dan tidak ada satupun data yang mengalami pelenyapan. Data yang dikirimkan oleh sumber (source) dan penerima (receiver) dapat terkirim dengan baik pada jarak jangkau $\leq 75 \mathrm{~m}$. Hal ini menandakan pada jarak ini data masih dapat terkirim dengan baik. Data pada jarak $80 \mathrm{~m}$ hingga $85 \mathrm{~m}$ mengalami perubahan penerimaan informasi pada penerima. Perubahan yang terjadi adalah lenyapnya satu karakter data yang telah dikirimkan oleh sumber. Data yang lenyap merupakan data ASCII yang hilang satu karakter baik data yang pertama dalam setiap pengirimannya, maupun data yang kedua dan ketiga. Hal tersebut dimungkinkan karena faktor alamiah berupa pelemahan pada sumber Gelombang Elektromagnetik (GEM) yang digunakan hanya memiliki jangkauan kerja pada jarak optimal $\leq 75 \mathrm{~m}$, sehingga untuk jangkauan antara $80 \mathrm{~m}$ hingga $85 \mathrm{~m}$ mengalami pelemahan yang mengakibatkan data tidak dapat terkirim dengan baik. Hasil pengambilan data pada jarak $90 \mathrm{~m}$ menunjukkan bahwa data tidak terkirim dengan baik. Kondisi ini disebabkan karena jangkauan jarak Xbee mengalami pelemahan energi. Pelemahan energi tersebut dikarenakan Xbee yang digunakan hanya memilik jangkauan $90 \mathrm{~m}$ sesuai datasheet. Data di atas merupakan hasil-hasil yang diperoleh pada pengukuran pagi hari pada cuaca cerah dan tidak berawan dan atau tidak hujan.

Tabel 2. Hasil pengambilan data pukul $14.00-16.00$

\begin{tabular}{|c|c|c|}
\hline No & Jarak (m) & Data $S$ dan $R$ \\
\hline 1 & 1 & 'x';'y';'z' \\
2 & 5 & 'x';'y';'z' \\
3 & 10 & 'x';'y';'z' \\
4 & 15 & 'x';'y';'z' \\
5 & 20 & 'x';'y';'z' \\
6 & 25 & 'x';'y';'z' \\
7 & 30 & 'x';'y';'z' \\
8 & 35 & 'x';'y';'z' \\
9 & 40 & 'x';'y';'z' \\
10 & 45 & 'x';'y';'z' \\
11 & 50 & 'x';'y';'z' \\
12 & 55 & 'x';'y';'z' \\
13 & 60 & 'x';'y';'z' \\
14 & 65 & 'x';'y';'z' \\
15 & 70 & 'x';'y';'z' \\
16 & 75 & 'x';'y';'z' \\
17 & 80 & 'x';'z' \\
18 & 85 & 'x';'z' \\
19 & 90 & Lenyap \\
\hline
\end{tabular}

$\mathrm{R}$ : receiver $; \mathrm{S}=$ source ;

Data diambil pukul 14.00-16.00

Data yang diperoleh berdasakan Tabel 2 menujukkan hasil yang sama dengan data yang diperoleh pada tabel 1. Hal yang menjadikan pembahasan dalam temuan ini adalah perbedaan kondisi waktu pengambilan data yang memberikan beberapa hasil yang relatif sama. Hasil pengambilan data antara jangkauan $1 \mathrm{~m}$ hingga $75 \mathrm{~m}$ memberikan gambaran bahwa data yang deperoleh sama dengan data yang diterima. Hal ini memberikan arti bahwa pada perbedaan waktu pengambilan data 


\section{ISSN: 2087-9946}

sebagai variasi perubahan temporal ternyata tidak memberikan kontribusi yang signifikan. Energi yang dipancarkan oleh sumber ini mengakibatkan kekuatan daya pancar GEM dari sumber masih dapat diterima dengan baik pada jarak tersebut, yaitu jarak $\leq 75 \mathrm{~m}$. Data yang diperoleh antara jarak $80 \mathrm{~m}$ hingga $85 \mathrm{~m}$ memberikan gambaran pula bahwa data masih dapat terkirim dari sumber menuju penerima, namun data yang diperoleh mengalami atenuasi energi GEM. Dengan adanya atenuasi tersebut menyebabkan data yang diterima menjadi lenyap satu karakter. Karakter ASCII yang hilang disebabkan karena pengaruh atenuasi yang mengakibatkan energi jangkauan menjadi berkurang. Pengambilan data pada jarak 90 m seperti yang tertera pada gambar berikut merupakan pengambilan data dengan jangakauan maksimum. Data yang diperoleh pada titik tersebut terjadi karena peristiwa atenuasi yang menjadikan energi sumber tidak sampai pada penerima. Tabel 2 merupakan hasil yang diperoleh pada saat kondisi cerah untuk waktu antara pukul 14.00 hingga pukul 16.00 .

Tabel 3. Hasil pengambilan data pukul $20.00-22.00$

\begin{tabular}{|c|c|c|}
\hline No & Jarak (m) & Data $S$ dan $R$ \\
\hline 1 & 1 & 'x';'y';'z' \\
2 & 5 & 'x';'y';'z' \\
3 & 10 & 'x';'y';'z' \\
4 & 15 & 'x';'y';'z' \\
5 & 20 & 'x','y';'z' \\
6 & 25 & 'x';'y';'z' \\
7 & 30 & 'x';'y';'z' \\
8 & 35 & 'x';'y';'z' \\
9 & 40 & 'x';'y';'z' \\
10 & 45 & 'x';'y';'z' \\
11 & 50 & 'x';'y';'z' \\
12 & 55 & 'x';'y';'z' \\
13 & 60 & 'x';'y';'z' \\
14 & 65 & 'x';'y';'z' \\
15 & 70 & 'x';'y';'z' \\
16 & 75 & 'x';'y';'z' \\
17 & 80 & 'x';'z' \\
18 & 85 & 'x';'z' \\
\hline
\end{tabular}

\begin{tabular}{|c|c|c|}
\hline No & Jarak (m) & Data $S$ dan $R$ \\
\hline 19 & 90 & lenyap \\
\hline
\end{tabular}

$\mathrm{R}$ : receiver $; \mathrm{S}=$ source ;

Data diambil pukul 20.00-22.00

Berdasarkan Tabel 3 di atas, hasil-hasil tersebut merupakan data perubahan variasi temporal dan dengan variasi spasial ditentukan pada jarak jangkau $1 \mathrm{~m}$ hingga pada batas jangkauan $90 \mathrm{~m}$. Dari data percobaan ini akan dilihat bagaimana karakter dari xbee terhadap beberapa gejala alam yang mana dengan keadaan ini xbee bekerja baik di semua kondisi perubahan waktu pengukuran. Untuk kelembapan medan pengambilan data diperoleh dengan kelembapan rata-rata $65 \%$. Untuk jarak $\leq 75$ $\mathrm{m}$ maka data terkirim dengan baik dan untuk jarak antara $80 \mathrm{~m}$ hingga $85 \mathrm{~m}$ data yang diterima lenyap satu karakter. Hal ini disebabkan oleh adanya gangguan sekitar tempat pengambilan data berupa kondisi teknis lapangan yang masih memungkinkan terjadi interferensi maupun refleksi gelombang yang dapat mempengaruhi hasil dari pengambilan data. Berikut ketiga pengiriman data yang tersaji dalam grafik (Gambar 2) yang menunjukkan data pengiriman yang memiliki hasil relatif sama.
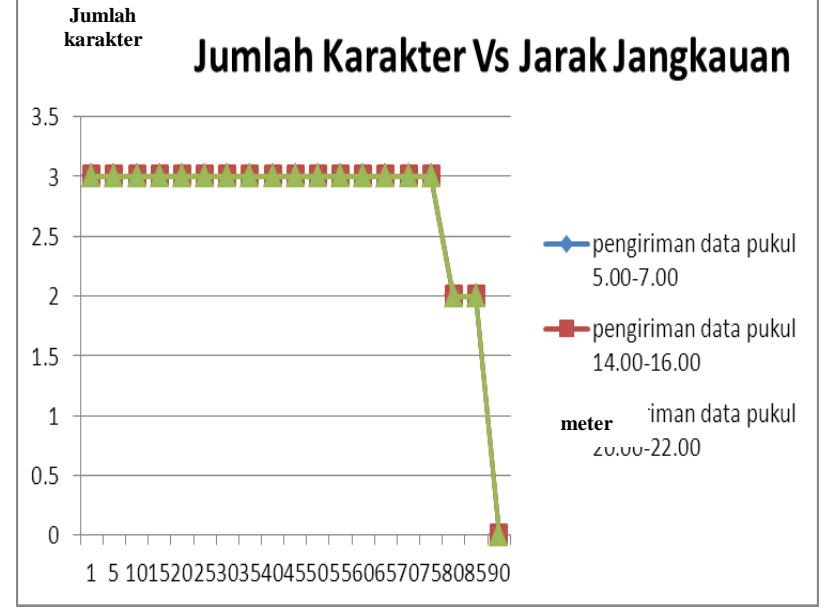

Gambar 2 Data pengiriman terhadap jarak jangkauan

Pelemahan yang terjadi seiring dengan bertambahnya jarak pengukuran merupakan hal yang logis sesuai teori, di mana pada teori menyebutkan energi yang dipancarkan 
ISSN: 2087-9946

seperti dalam skema vektor pointing akan berkurang energinya seiring dengan pertambahan jarak, sebab terdapat faktor atenuasi pada persamaan tersebut sebesar $\mathrm{e}^{-\mathrm{kZ}}$ yang mutlak mempengaruhi energi propagasinya. Untuk itulah mengapa ketika jarak bertambah, faktor atenuasi amplitudo tersebut ikut mengecil dan menjadikan energi mengecil pula. Oleh karena itu untuk harga ' $z$ ' yang semakin bertambah akan menyebabkan besarnya daya jangkauan memiliki harga sebaliknya yaitu semakin berkurang mengecil dan akhirnya nol. Pada titik yang memiliki harga jangkauan maksimal tersebut yaitu pada titik $90 \mathrm{~m}$, memili titik energi yang hampir nol sehingga tidak mampu mengirimkan data.

\section{SIMPULAN DAN SARAN}

Kesimpulan yang dapat diambil adalah data yang diperoleh saat pengiriman terbaik adalah pada jangkauan $\leq 75 \mathrm{~m}$. Semua data dapat terkirim dengan baik tanpa ada data yang lenyap saat mengalami pengiriman data. Selain itu, untuk jangkauan antara $80 \mathrm{~m}$ hingga $85 \mathrm{~m}$ didapatkan hasil yang cukup baik dengan pengiriman data yang lenyap satu karakter. Untuk data yang terkrim pada jarak $90 \mathrm{~m}$ maka dapat diambil kesimpulan bahwa data sudah tidak dapat terkirim dengan baik. Secara umum jarak yang dicapai oleh Xbee pada jarak kurang dari 90 $\mathrm{m}$ dan tidak ada pengaruh yang signifikan terhadap perubahan variasi waktu pengukuran.

Saran yang dapat diambil adalah berkenaan dengan proses pengambilan data agar pada saat pengambilan data selanjutnya dapat dilakukan pada semua kondisi waktu yang dapat divariasi. Selain itu juga pengambilan data dilakukan pada kondisi cuaca yang berbeda agar dapat dipelajari bagaimana konsep fisis maupun beberapa kendala teknis untuk keperluan aplikasi dari penelitian pada multidisiplin yang lain.

\section{UCAPAN TERIMAKASIH}

Ucapan terimakasih yang sedalamdalamnya untuk Bapak Tjipto Prastowo, Ph.D yang banyak memberikan ilmu dan pengalaman hidup untuk menjadi mahasiswa yang lebih baik.

\section{DAFTAR PUSTAKA}

Ergen, S. C. (2005). ZigBee/IEEE 802.15.4

Summary. In Ergen. Berkeley,

California.

Griffiths, D. J. (1999). Introduction to Electrodynamics 3rd ed. A. Reeves, Ed. New Jersey: Prentice Hall.

Jamil, T. (2008). "Design and Implementation of a Wireless Automatic Meter Reading System.”. London: Proceedings of the World Congress on Engineering Vol I.

Nugraha, Y.P. (2013). Transmisi Data Melalui Gelombang Elektromagnetik Dengan Menggunakan Modul Xbee Pro 24-Aci-001. Surabaya: Jurnal Inovasi Fisika Indonesia. Volume 02 Nomor 03 Tahun 2013, ISSN : 2302-4216

Nugraha, Y.P. (2013). Transmisi Data Melalui Sistem Komunikasi Frekuensi Radio Dengan Menggunakan Modul Xbee Pro 24-Aci-001. Tangerang: Seminar Nasional Fisika 2013 LIPI, ISSN 2088-4176

Rao, V. P. (2005). The simulative Investigation of Zigbee / IEEE 802.15.4. Dresden: Dresden Univesity Of Technology. 